\title{
INDIOS CONQUISTADORES EN LA DESCRIPCIÓN DE LA CIUDAD Y PROVINCIA DE TLAXCALA (1584) DE DIEGO MUÑOZ CAMARGO*
}

\author{
Alejandro Viveros Espinosa \\ Universidad de Chile, Santiago de Chile, Chile \\ aviveros@u.uchile.cl
}

\section{RESUMEN / ABSTRACT}

El objetivo de este escrito es posicionar un acercamiento crítico en torno al lugar de los indios en la conquista y colonización de Mesoamérica. Utilizaremos la noción de "indios conquistadores" en el análisis e interpretación de la Descripción de la ciudad y provincia de Tlaxcala (1584) de Diego Muñoz Camargo. Para ello, desplegaremos cuatro momentos relacionados. El primero refiere a un posicionamiento en torno a la noción de indios conquistadores. El segundo responde a un acercamiento al contexto de producción y los contenidos de la Descripción. El tercero remite a los tlaxcaltecas como indios conquistadores y releva elementos presentes tanto en el texto escrito de la Descripción como en una selección de sus imágenes. Finalmente, el cuarto releva el propósito de la narración histórico-literaria de Muñoz Camargo y la participación tlaxcalteca como conquistadores en Mesoamérica.

Palabras clave: Indios conquistadores, Diego Muñoz Camargo, Tlaxcala, colonización, Mesoamérica.

\section{INDIAN CONQUISTADORS IN DIEGO MUÑOZ CAMARGO'S DESCRIPCIÓN de la Ciudad y Provincia de Tlaxcala (1584)}

This paper proposes a critical approach about the place of the Indians in the Mesoamerican Conquest and colonization. To this purpose, we will use the notion of "Indian Conquistadors" to analyze and interpret Diego Muñoz Camargo's Descripción de la ciudad y provincia

Resultado del proyecto CONICYT-FONDECYT Iniciación No 11160012 titulado, "Convivencia interétnica y traducción cultural. Aproximaciones sobre el contenido filosóficopolítico de las crónicas de indios en el mundo cultural novohispano (1576-1650)”. 
de Tlaxcala (1584). We will follow four interconnected approaches. The first proposes a theoretical and methodological background about the notion of Indian Conquistadors. The second refers to the Descripcion's context of production and its contents. The third uses the notion of Indian conquistadors to reveal some specific aspects within the written text of the Descripción and in a selection of its well-known images. Finally, the fourth reconsiders the purpose of Muñoz Camargo's hitorical-literary narration about the tlaxcalans'collaboration as conquerers in Mesoamerica.

KEYWords: Indian Conquistadors, Diego Muñoz Camargo, Tlaxcala, Colonization, Mesoamerica. Recepción: 12/12/17

Aprobación: 15/04/2018

La guerra y el valor han hecho más cosas grandes que el amor al prójimo. No vuestra compasión, sino vuestra valentía es la que ha salvado hasta ahora a quienes se hallaban en peligro (Nietzsche 198).

En sentido casi literal, los indios de América fueron los conquistadores -o destructores- de su propio mundo, en beneficio de los invasores europeos. Una y otra vez la historia se repitió: unos indios sometieron a otros, permitiendo a los europeos dominar vastas zonas del Nuevo Mundo. Gran parte, o mejor dicho, la mayor parte de la conquista de América por los europeos fue propiciada y realizada por las luchas de unos indios contra otros, luchas que fueron dirigidas por puñados de hombres blancos que astutamente aprovecharon las antiquísimas rivalidades entre indígenas (Powell 165).

1521, avanzan los soldados olvidados, los indios aliados. Son las tropas de Cortés entrando a México-Tenochtitlan. Oscurecidos por la narración colonial, las tropas indias constituyen los aliados olvidados y denostados de la conquista y la colonización novohispana. Este artículo procura profundizar en la célebre Descripción de la ciudad y provincia de Tlaxcala (1584) de Diego Muñoz Camargo a través de la noción de indios conquistadores, con el objetivo de reconocer la enunciación de los indios vencedores, en este caso, la visión tlaxcalteca de la conquista y colonización.

Con este propósito dividiremos nuestro análisis en cuatro momentos. El primero responde a una aclaración conceptual en torno a la noción de indios conquistadores. El segundo momento refiere a la Descripción articulando una comprensión general del texto, de sus contenidos y de sus materiales 
visuales. Un tercer momento releva la posición de los tlaxcaltecas como indios conquistadores a partir de algunos ejemplos específicos presentes en la Descripción. Finalmente, en un cuarto momento, de carácter conclusivo, reconsideraremos el propósito de la narración histórico-literaria de Muñoz Camargo en torno a la participación tlaxcalteca como conquistadores y aliados. Ulteriormente, buscamos conducir una interpretación que profundiza en las motivaciones de los tlaxcaltecas para su colaboración y alianza, en este caso, con la empresa de conquista y colonización de Nueva España y otras latitudes.

\section{EN TORNO A LA NOCIÓN DE INDIOS CONQUISTADORES}

En términos históricos y filosóficos, la noción de "indio" es el antecedente ineludible y como tal nos conduce a un asunto complejo, hasta cierto punto todavía confuso y difícil. Más aun cuando se le agrega la noción de "conquistador". Sin ánimo de resolver la complejidad y polisemia del concepto de indio, podemos señalar que el ejercicio de "invención" del indio es congruente con el de América (O’Gorman 15-54). A través del término indio es plausible la reconstrucción cultural e identiaria de una multiplicidad de identidades particulares. Podríamos decir que la noción de indio es capaz de vectorizar su condición de construcción cultural operada e impuesta por el orden colonial, funcionalizando y amalgamando diferentes identidades en una siempre ambigua y evanescente. En este ejercicio sostenemos que aquellos llamados "indios" fueron parte activa y determinante en diferentes dimensiones, superando una lectura revisionista de su participación y proporcionando nuevas entradas para el problema del indio y sus acciones en la conquista y la colonización del Nuevo Mundo. Veamos esto.

Respecto de la noción de "indios conquistadores" es necesario también reconocer como antecedente su relación con los términos: "indios amigos" e "indios auxiliares". Brevemente, podemos indicar que la incorporación del

\footnotetext{
"Indios amigos" o "indios auxiliares" son términos que se otorgan a aquellos naturales que colaboraron en diferentes acciones durante las guerras de conquista y colonización del Nuevo Mundo. La distinción entre "indio amigo" e "indio de guerra", muy presente, por ejemplo, en la crónica de Bernal Díaz del Castillo, nos permite identificar la presencia o ausencia de actos de beligerancia como el componente constitutivo del término. Para el término "indios auxiliares" es prudente retomar el sentido militar que tiene como antecedente a las "tropas auxiliares romanas", esto es, tropas compuestas por individuos sin ciudadanía romana, y que
} 
indio al orden colonial incluye una distinción específica para aquellos que colaboraron de diversas maneras en las acciones de conquista y colonización desarrolladas en el Nuevo Mundo. En las crónicas de la conquista de México, los indios auxiliares son expuestos desde una relación vasallática, exaltando su compromiso voluntario hacia la corona (Cortés 32, Díaz del Castilo 402). La relación vasallática contiene la comprensión tardomedieval de un "vínculo de fidelidad", de mutuo acuerdo, en el cual las contrapartes (señor y súbdito) comprometen su colaboración confome a una relación jerárquica. Entonces, desde la perspectiva del conquistador, toda vez que los indios aceptaban sujetarse a la corona, quedaban también obligados a prestar auxilio económico y militar. No obstante, desde la perspectiva de los indios, el apoyo a las empresas de conquista parece tener otro matiz. Es plausible pensar que la colaboración prestada a las huestes hispanas pudo ser comprendida más bien en términos de una "alianza" entre iguales, algo más cercana a la comprensión político-religiosa de las tradiciones guerreras mesoamericanas (Domínguez 17-45, López Austin 48-77).

Pues bien, respecto de los indios auxiliares es necesario remarcar la lectura canónica de Philip Powell y su célebre La Guerra Chichimeca (1550-1600). Powell analiza el conflicto bélico irregular entre el orden colonial y grupos de indios habitantes de las zonas áridas del altiplano centro-norte mexicano y que tiene su origen en un proceso de expansión, especialmente motivado por la producción de plata y otros minerales. En su análisis se reconoce el lugar y la labor ejercida por los "indios auxiliares" tanto a nivel de su participación militar como en su condición de colonizadores de las nuevos territorios, destacando a los "indios flecheros" y "milicias de indios" como elementos fundamentales en la extensión y control de los territorios de frontera (Powell 165-178).

operaban en territorios de frontera (Holder 12-57). Así también, recogemos la distinción entre "indios amigos" e "indios auxiliares" de Andrea Ruiz Esquide en su Los indios amigos en la frontera araucana: "Puede afirmarse entonces, que aquellos que actuaron como amigos en el siglo XVI eran indios de servicio de los españoles: indígenas de encomienda y yanaconas. Para distinguirlos de los de la centuria siguiente, se les puede denominar indios auxiliares" [...] "Se puede, entonces, distinguir claramente entre los amigos del siglo XVI y aquellos de la siguiente centuria, pues su origen y su calidad eran distintos. Es por esas diferencias y clara distinción entre uno y otro tipo de amigos, que es apropiado hablar de amigos propiamente tales, sólo en el contexto de la historia fronteriza, es decir desde las últimas décadas del siglo XVII en adelante" (24). 
Sin embargo, el enlace entre el indio auxiliar y el indio conquistador remite a una perspectiva relativamente reciente, para la cual podemos distinguir algunos antecedentes específicos. Matthew Restall -desde la Nueva Filología ${ }^{2}$ - en su célebre Seven Myths of the Spanish Conquest procede hacia la problematización del lugar de los indios durante los procesos de conquista y colonización en el Nuevo Mundo. El objetivo de Restall es posicionar las construcciones de la historia convencional que ocultan aspectos relevantes del proceso de conquista de América. Restall sostiene que hubo participación directa de los indígenas en el derrocamiento de los grandes imperios precolombinos. Como ejemplo de ello refiere a la colaboración tlaxcalteca primero con las huestes de Cortés en Mexico-Tecnohtitlán y luego en otra latitudes, particularmente, en el área maya (Restall 46-48).

Asimismo, Matthew Restall y Ben Vinson en su texto titulado Black Soldiers, Native Soldiers. Meanings of Military Service in the Spanish American Colonies profundizan en la figura del servicio militar colonial donde relevan la participación de indios y africanos en la conquista y colonización del Nuevo Mundo (especialmente en el siglo XVII y XVIII). El escrito identifica las acciones de "indios flecheros", "indios amigos", "indios aliados" y refiere al lugar de los tlaxcaltecas como ejemplo paradigmático de la colaboración militar nativa.

En su propuesta se distingue el impacto del servicio militar en indígenas $\mathrm{y}$ afrodescendientes otorgando un lugar central al modo en el cual el orden colonial coopta sus servicios al momento de integrarlos como "milicianos" (militiamen) y cómo en éstos se abren espacios para el ascenso social y la interacción cultural. Restall y Vinson remarcan una diferencia sustancial, mientras el fenotipo rige para la composición de la tropas de afrodescendientes, para las tropas de indios hubo espacios para la etnicidad (ethnicity), permitiendo a éstos integrar tropas ligadas a sus identidades particulares (tlaxcaltecas, mexicas, texcocanos, xochimilcos, etc.), siendo, además, dirigidos por un "indio cacique". En términos de la construcción de la noción de indios

\footnotetext{
Respecto de la Nueva Filología (New Philology) o "etnohistoria filológica" (philological ethnohistory) especialmente porque relevan las posibilidades de interpretación en las múltiples producciones escriturales y pictográficas de sujetos "indios" durante el periodo colonial (Lockhart, Introduction 1-24, Restall, Seven Myths 27-43). Estas producciones alcanzan un renovado potencial crítico precisamente debido a su atención sobre los contextos lingüístico-culturales (nahua e hispano) y sus condiciones de transferencia y circulación dentro mundo colonial novohispano (Lockhart, The Nahuas 326-373, Schroeder 1-14).
} 
conquistadores es importante señalar que Restall y Vinson posicionan y problematizan el lugar del indio (y de los afrodescendientes), subrayando los motivos del orden colonial junto con los beneficios y resguardos obtenidos por sus servicios.

Ahora bien, la noción de indios conquistadores se consolida con la publicación de Indian Conquistadors, un trabajo colaborativo editado por Laura Matthew y Michel Oudijk que procura articular una comprensión amplia de la noción de indios conquistadores. Dentro de los ensayos contenidos en Indian Conquistadors remarcamos el titulado Mesoamerican Conquistadors in the Sixteenth Century de Matthew Restall y Michel Oudijk. Ahí se analizan cuatro categorías que exponen los modos de colaboración entre indios conquistadores (aliados y auxiliares) y las tropas hispanas. La primera categoría refiere al número de indios auxiliares (Indian auxiliaries) o indios amigos (friendly Indian). La segunda, al lugar de los indios aliados en las campañas militares, más allá de los ejemplos conocidos de la conquista de México (1519-1521). La tercera posiciona al rol crucial de los auxiliares no combatientes, es decir, la participación de indios como espías o intérpretes o bien como porteros o cocineros, entre otras labores. La cuarta muestra cómo la conquista hispana imitó patrones precolombinos para su expansión en Mesoamérica. Esto acontece debido a la correspondencia entre las rutas comerciales prehispánicas y las rutas de la conquista, lo que permitió -en el camino- afianzar una multiplicidad de alianzas políticas, militares y económicas, que fueron fundamentales para el proceso de conquista de México-Tenochtitlan y de otros territorios. Restall y Oudijk focalizan su investigación en documentos relacionados con peticiones y demandas hechas por los "conquistadores mesoamericanos" (Mesoamerican conquistadors) y enviadas a la corona durante el siglo XVI. Destaca el ejercicio de desmontaje de múltiples lecturas esencialistas sobre los conquistadores y sobre los indios junto con la reafirmación de la visión indígena en el contexto de la reconstrucción del mundo cultural postconquista.

Interesante es el aporte de John Chuchiak, quien en su ensayo Forgotten Allies: The Origins and Roles of Native Mesoamerican Auxiliaries and Indios Conquistadores in the Conquest of Yucatan, 1526-1550 recoge una serie de evidencia historiográfica que permite reconocer no solo el complejo proceso de movilización de personas en las actividades de conquista y colonización, sino que más bien al papel jugado por los indios aliados. Chuchiak identifica momentos consecutivos de incoporación de los indios aliados en el desarrollo de las campañas militares, específicamente, en las empresas de conquista hechas 
por Francisco de Montejo, las célebres "entradas a Yucatán". Asimismo, a partir de las peticiones de libertad de tributo elaboradas por sobrevivientes de las campañas militares, Chuchiak logra reconstruir la sistemática omisión de la recompensa prometida por sus servicios e incluso la demanda e imposición de devoluciones e impuestos. Sostiene John Chuchiak en Forgotten Allies. The Origins and Roles of Native Mesoamerican Auxiliaries and Indios Conquistadores in the Conquest of Yucatan, 1526-1550:

La misma generación de conquistadores españoles, que deben a estos indios conquistadores sus vidas y el éxito de la conquista en sí, fueron a sus tumbas sin reconocer los esfuerzos o recompensar sus luchas. Mientras una larga línea de indios conquistadores e indios hidalgos continuaron basando sus posteriores reclamos de libertad de servicios y tributos en las acciones de sus antecesores, solo un puñado de españoles recordó a los aliados olvidados. Pocos tuvieron tal corage y convicción como el capitán Francisco de Bracamonte, él mismo un comandante de una columna combinada de españoles y muchos cientos de nahuas auxiliares, cuando recordó a aquellos aliados olvidados y testificó a la corona, "Yo puedo decir con total honestidad que sin ellos nunca hubieramos conquistado esta tierra" ${ }^{3 "}(215)$.

Chuchiak posiciona la noción de indios conquistadores en directa relación con el ocultamiento o desconocimiento de su labor y ayuda en la conquista. La referencia al capitán Bracamonte evidencia la persistente búsqueda de reconocimiento y recompensa por sus acciones de auxilio y colaboración, y que configura el triste camino que los aliados olvidados, los indios conquistadores, hubieron de recorrer frente a la omisión y la negación de sus resguardos.

Destacamos también el aporte de Raquel Güereca y su libro Milicias indigenas en la Nueva España, quien realiza un acercamiento desde un enfoque jurídico que considera el derecho indiano y los derechos de guerra.

3 The very generation of Spanish conquistadors that owned these indigenous conquistadors their lives and the success of the conquest itself went to their graves without recognizing their efforts or rewarding their struggles. While a long line of indios conquistadores and indios hidalgos continued basing their later claims to freedom of services and tributes on actions of their ancestors, only a handful of Spaniards remembered the forgotten allies. Few had such courage and conviction as Captain Francisco de Bracamonte, himself a commander of a combined column of Spaniards and several hundred Nahua auxiliaries, when he remembered those forgotten allies and testifed to the Crown, "I can say in all honesty that without them we would never have conquered this land" (Chuchiak 215). 
Destaca su análisis sobre los modos de institucionalización de la colaboración militar indígena desde los antecedentes de la incorporación de las "milicias de indios" durante el siglo XVI hasta su decadencia con la reconstrucción del aparato militar imperial a finales del siglo XVIII. En su propuesta se retoma y despliega el lugar y la activa participación del indio en la conquista, utilizando para ello la noción de indios conquistadores (Güereca 11-22).

Como hemos procurado delinear en la revisión del término, es posible sostener que la noción de indios conquistadores nos abre a considerar un punto de vista oculto en el cual el compromiso de los indios con las acciones bélicas no está cerrado a una dimensión subalterna o pasiva, vasallática, sino que a un interés o motivación en el cual una alianza o bien una relación colaborativa parece ser parte del contenido semántico del término. En cierto sentido, la noción de indios conquistadores intenta relevar la dimensión humana de la guerra y el conflicto y, cómo desde ésta es posible volver a preguntar por la construcción de relaciones de supervivencia y colaboratividad. Finalmente, la noción de indios conquistadores nos lleva a poner en escena al indio vencedor, a aquel indio que pudo sostenerse en la tormenta y en ella encontrar su lugar.

\section{EN TORNO A LA DESCRIPCIÓN DE DIEGO MUÑOZ CAMARGO}

Es conveniente preguntar, inicialmente, ¿quién es Diego Muñoz Camargo? Charles Gibson (1950) enuncia la autoría y la identidad de Diego Muñoz Camargo (1528-1599), ulteriormente funcionalizadas desde su condición de mestizo emparentado con familias de abolengo indígena y de su condición bilingüe (náhuatl y español). Podemos relevar algunos elementos biográficos que pueden colaborar en nuestra indagación. Gibson afirma que Diego Muñoz Camargo parece haber gozado de posiciones importantes tanto en asunto oficiales como en negocios individuales, asociados a la ganadería y la producción de sal. Destaca también su cercanía con el orden colonial, lo cual le permite gozar de la confianza de los gobernantes tlaxcaltecas.

Nuevamente, ¿quién es Diego Muñoz Camargo? Es posible responder esta pregunta en virtud de su producción histórico-literaria. Brevemente, posicionamos el concepto de "crónica mestiza" para reconocer una dimensión histórico-literaria en las producciones escriturales realizadas durante la primera etapa de la colonización americana. Así define este concepto Martin 
Lienhard en La crónica mestiza en México y el Perú hasta 1620: Apuntes para su estudio histórico-literario:

Atribuimos el carácter "mestizo" a aquellas crónicas que, casi independientemente del origen étnico de sus autores (indígenas, mestizos, españoles), reelaboran materiales discursivos o reales de la historia americana a través de unos procedimientos narrativos (verbales y/o pictográficos) de tradición heterogénea: indígena y europea. (105)

A través del concepto de "crónicas mestizas", funcionalizadas como trasfondo teórico-metodológico, es posible elaborar un ejercicio teórico-crítico relativo a un discurso identitario en construcción que despliega "procedimientos narrativos heterogéneos" en apertura a nuevos horizontes de pregunta y que configuran, como señala Martín Lienhard, "las premisas de una nueva conciencia global, histórica, política y cultural" (107).

En este sentido, dos crónicas mestizas componen el centro de la producción histórico-literaria de Muñoz Camargo, a saber, la Descripción (1584) y la Historia de Tlaxcala (1590). Ambas encadenan un relato marcado por intertextualidad. Quizá la Historia es una obra mejor lograda al momento de reconstruir los eventos relativos a la provincia de Tlaxcala. Lo que se explica, precisamente, porque es una producción posterior a la Descripción. En cierto sentido, en la Historia se evidencia un estilo y una posición de enunciación mucho más afinada en torno a la composición de un relato sobre la historicidad de aquellas tierras. No obstante, queremos pensar a la Descripción y la Historia como textos entremezclados, es decir, como experiencias diferentes relativas a un mismo y único objetivo, a saber, dar a conocer los avatares de esas tierras que, a la luz de su participación en la conquista y el orden colonial, merecen un trato especial.

Por comisión de Alonso de Nava, Alcalde Mayor de Tlaxcala, alrededor de 1580 Diego Muñoz Camargo comienza a escribir su Descripción de la ciudad y provincia de Tlaxcala, la cual fue terminada en 1584, además de ser entregada personalmente al rey Felipe II durante la embajada de 1585. La obra integró la Biblioteca de El Escorial, y sorprendentemente aparece integrando la colección que William Hunter (1718-1783) donara a la Universidad de Glasgow. Allí se encuentra en la actualidad y es conocido como el Manuscrito de Glasgow. Dentro de los trabajos críticos en torno al Manuscrito, utilizaremos la realizada en versión facsimilar por René Acuña 
$(1981)^{4}$ y la versión paleografiada por el mismo Acuña y publicada en 2000, ambas tituladas como Descripción de la ciudad y provincia de Tlaxcala.

La Descripción como tal es una obra compleja en su estilo y en su objetivo. Es un texto escrito de forma continua, inicia con la "Instrucción y Memoria", que consta de cincuenta preguntas, luego presenta una dedicatoria al rey Felipe II y una aclaración de intenciones en torno a la redacción. A continuación se divide en dos libros, el primero contiene veinte capítulos en prosa, el segundo, algo más caótico, contiene la "cuenta de los años de los indios", un "calendario índico de fray Francisco de las Navas", una explicación "de los años" y "de los bisiestos", junto con una aclaración de las cuentas de "días, meses y años" cristianos verificados en la "Cuenta de Antonio de Guevara". A ello agrega un capítulo sobre la "fauna y la flora de Tlaxcala", para finalizar con siete capítulos dedicados a las "cabeceras de Ocotelulco, Quiyahuitztlán, Tepeticpa y Tizatlán”, a "capitanes famosos”, “divisas y armas" y una indicación sobre los asuntos no tratados en la Descripción.

La Descripción debe cumplir con los estándares de una relación geográfica siguiendo la "Instrucción y Memoria" (Muñoz Camargo, Descripción 27-32) que remite a una descripción territorial focalizada grosso modo tanto en ríos y montañas, en asentamientos y poblaciones, como en las potencialidades económicas y políticas. Frente a este escenario, Muñoz Camargo decide intervenir proporcionando una perspectiva mucho más específica. Dentro de la composición del texto alfabético de la Descripción podemos reconocer, primero, que hay un orden propio y una desproporción en el tratamiento de algunos temas; y que además hay una intención por historizar más allá que meramente informar. Hay en la Descripción un estilo heterogéneo y aglutinante que procura referir a las cuatro cabeceras de Tlaxcala, describiendo a veces repetitivamente la información correspondiente a cada una.

4 Existe una edición facsimilar de 1981 y otras dos versiones palegrafeadas realizadas en 1984 y 2000. Como hemos señalado utilizaremos la edición facsimilar para el análisis de los imágenes. No obstante, esta edición no estuvo exenta de polémica. Hubo una acusación de "piratería académica" por parte de Hanns J. Prem sobre el trabajo de Acuña y publicada en una reseña sobre la edición facsimilar en el Zeitschrift für Ethnologie. Esto condujo a una fuerte defensa del trabajo realizado por Acuña y que podemos encontrar en su texto: "Descripción de la ciudad y provincia de Tlaxcala. Una respuesta a Hanns J. Prem" donde queda en clara evidencia la relevante y sincera labor científica desarrollada en la edición y divulgación de la Descripción. 
La Descripción incorpora dos ruedas calendáricas y explicaciones de las mismas, que responden al "calendario índico de fray Francisco de Navas". En la primera se explican días, semanas, meses y años, y en la segunda se explican los meses según el calendario lunar de veinte días. Cada una contiene anotaciones e indicaciones detalladas y aclarativas en los modos en que los naturales medían el tiempo (Muñoz Camargo, Descripción 222233). En su exposición calendárica, Muñoz Camargo canaliza el interés por el tiempo -como problema filosófico-en el mundo cultural mesoamericano. Nancy Farriss, en su artículo titulado Recordando el futuro, anticipando el pasado. Tiempo histórico y tiempo cósmico entre los mayas de Yucatán, problematiza este asunto a partir de una dicotomía entre una comprensión del tiempo estacionaria y cíclica determinada por oposiciones complementarias, y una comprensión lineal o teleológica, específicamente en la intervención del horizonte cultural cristiano presente en las crónicas o relatos producidos por indios coloniales del área maya. Sin embargo, es posible establecer que la Descripción se concentra más bien en sintonizar o bien acomodar el problema del tiempo a una explicación cristiana. El interés por el tiempo "pone en escena" que bajo la explicación del calendario cristiano, Muñoz Camargo negocia con las modalidades de la comprensión nahua del tiempo. El detalle en la explicación de la "rueda de los meses" y las celebraciones asociadas a días específicos son ejemplo de ello.

Por lo tanto, la Descripción nos abre a reconocer en ella los elementos en negociación y traspaso, y cómo éstos se muestran en dos códigos, uno alfabético y otro visual. Los tópicos tratados en el código alfabético, como hemos indicado, responden en amplios rangos al cuestionario ("Instrucción y Memoria"). A ello agrega Muñoz Camargo ciento cincuenta y seis figuras o imágenes, muchas de ellas intervenidas con elementos alfabéticos explicativos. Cada una de las figuras ocupa una página dibujada a pluma en tinta negra sin colorear; ochenta de ellas coinciden - con algunas variantes- con las pinturas del célebre Lienzo de Tlaxcala .

\footnotetext{
Producido circa 1552, el Lienzo de Tlaxcala es portador de la percepción tlaxcalteca de la conquista de México. Sus escenas corresponden a las que adornaban el cabildo de Tlaxcala. Dentro de la ediciones del Lienzo podemos destacar el canónico trabajo de Alfredo Chavero, quien reproduce en una versión analítica las escenas que lo componen. El Lienzo constituye uno de muchos materiales o imágenes producidas con anterioridad y durante el proceso de colonización novohispana. La correlación entre las imágenes del Lienzo y la Descripción ha sido trabajada por Andrea Martínez a partir del análisis de los contextos de producción de
} 
Siguiendo lo señalado por Acuña (1981) en el Estudio preliminar de su edición facsimilar, las ciento cincuenta y seis imágenes de la Descripción se pueden clasificar en cuatro series. Brevemente, la primera serie (Imágenes 1-19) refiere a las cuatro cabeceras de Tlaxcala, a la predicación evangélica franciscana, a los templos y los juegos antiguos, al ajusticiamiento de algunos caciques, al modelo habitacional de Xicoténcatl, a la plaza y al monasterio de Tlaxcala y, finalemente, a las provincias y reyes que conquistó Cortés previo a su llegada a Tlaxcala. Sostiene René Acuña: "Se puede observar hasta aquí que la narración pictórica no sigue orden alguno" (34). La segunda serie (Imágenes 20-25) corresponde a imágenes de Cortés, Colón, Pizarro y sus ofrendas a Carlos V y Felipe II. Aquí, René Acuña sostiene: "Son escenas alegóricas sueltas, relacionadas unas con otras por el gran tema del descubrimiento y conquista del Nuevo Mundo. Se corresponden con los que dice Muñoz Camargo que había pintadas en la sala y Audiencia capitulares de la ciudad de Tlaxcala" (34).

La tercera serie (Imágenes 26-75) remite a las batallas que los tlaxcaltecas libraron en alianza con los españoles en la conquista de México-Tenochtitlan, donde podemos reconocer que las imágenes tampoco se ajustan a una cronología estricta. La cuarta serie (Imágenes 76-156) desarrolla el lugar de los tlaxcaltecas en la conquista y colonización de otras provincias y latitudes, a saber, las provincias de Pánuco, del México occidental, zonas específicas de Centroámerica (principalmente Guatemala, El Salvador y Nicaragua) y la provincia de Oaxaca, finalizando todo en "Cipolla", con "la entrada que hizo Franco Vazquez de Coronado en tiempo de don Antonio de Mendoza".

En rigor, la descripción visual de conquista y colonización de Nueva España relatada por Muñoz Camargo se extiende desde 1519 hasta 1542. En la Descripción, los elementos visuales (en términos complementarios a la narración alfabética) nos muestran y se enlazan claramente con los objetivos

ambos. Martínez sostiene como hipótesis que el Lienzo es "una obra colectiva encargada por el cabildo indio de Tlaxcala a uno o varios dibujantes, tanto en su versión mural como en su versión transportable" (153). Destacamos también a Manuel Nuñez Rodríguez (2012) quien releva la forma específica y alternativa de "escribir la historia" que se encuentra en el Lienzo. Nuñez Rodríguez entiende el desarrollo de las imágenes del Lienzo desde una "dimensión mestiza", es decir, la fusión entre la tradición indígena y la hispana. Respecto del lugar de la imagen en el mundo mesoamericano es posible considerar el trabajo de Serge Gruzinski. Así también, respecto del contenido de los códices mesoamericanos y de la continuidad de escritura pictográfica pre y postconquista destacamos el trabajo de Pablo Escalante. 
políticos donde los tlalxcaltecas son conquistadores y, en ese contexto, son también pacificadores y civilizadores.

\section{LOS TLAXCALTECAS COMO INDIOS CONQUISTADORES}

La Descripción es un texto donde es posible reconocer el gesto histórico-literario que retoma el legado de los indios conquistadores. Queremos profundizar en la Descripción y escuchar la voz tlaxcalteca como leal súbdito, merecedor de fueros y beneficios por los servicios prestados. En la Descripción se relatan diferentes momentos en los cuales se exponen las decisiones político-militares de los naturales de Tlaxcala. Dentro de ellos destacamos los referidos a la respuesta que entregan las cuatro cabeceras frente a la exigencia de rendición por parte de los mexicas. Sostiene Diego Muñoz Camargo, "Señores muy poderosos, Tlaxcala no [o]s debe vasallaje ni, desde que salieron de las Siete Cuevas, jamás reconocieron con tributo ni pecho a ningún rey ni principal del mundo, porque siempre han conservado su libertad" (180). Esta perspectiva conduce el conflicto entre Tlaxcala y México-Tenochtitlan, en el cual se desarrolla un relato que explica la posición política de Tlaxcala en tiempos precortesanos. Sobre ello aclara Muñoz Camargo en la Descripción de la ciudad y provincia de Tlaxcala:

Y, como hubiesen los mexicanos tecnohcas sujetado la mayor parte deste nuevo mundo y que [su señor] no tuviese ya que ganar desde la Mar del Sur a la del norte, y todo lo que tuviese por suyo, procuró muy a su salvo tomar la provincia de Tlaxcalla y sujetarla, así como había hecho a las demás. Y ansí, los mexicanos, con ánimo denodado, les dieron tantos recuentros y escaramuzas, hasta que los vinieron a acorralar dentro de pocos años en sus $\mathrm{p}$ [ro]pias tierras y provincia, donde los tuvieron cercados más de 60 años, necesitándolos de todo cuanto humanam[en]te los pudieron necesitar, por no tenían algodón con que se vestir, oro ni plata con que se adornar, ni plumería verde de otras colores para sus galas, que es la que más estimaban para sus divi[s]as y plumajes, ni cacao para beber, ni sal para poder comer (180-181).

Más allá de los sesenta años de asedio mexica, los tlaxcaltecas -en voz de Muñoz Camargo- sufren las consecuencias de ser "enemigos necesarios" en una comprensión político-sacrificial de la guerra. Desde ahí la constante 
belicosidad hacia Tlaxcala se explica claramente. Entonces, la guerra funciona como asunto religioso y sacrificial determinante y con ello también genera la necesidad de enemigos que permitan continuar con las prácticas sacrificiales $\mathrm{y}$, ciertamente, con la formación de nuevos guerreros. Tlaxcala es el productor de enemigos y tiene ese lugar dentro de las guerras religiosas-sacrificales de los mexicas.

Sin embargo, con la llegada de Cortés el escenario del conflicto cambia radicalmente. No es menor la decisión política de integrar las huestes del conquistador y, por ello, la construcción de esta alianza nos permite relevar el lugar de los tlaxcaltecas como indios conquistadores. La alianza con Cortés es descrita a través de una escena que nos habla de una "plática y razonamiento" entre el conquistador y las cabeceras tlaxcaltecas. Sobre ésta sostiene Muñoz Camargo en la Descripción de la ciudad y provincia de Tlaxcala:

Y, en esta plática y razonamiento, dicen los tlaxcaltecas afirmativam[en] te que les prometió HER[NAN]DO CORTÉS que, si Dios n[uestro] señor les daba victoria, habrían parte de todo lo que [se] conquistase, ansí de despojos de oro y otras riquezas [como de] provincias y repúblicas, especialmente la ciudad y provincia de Huexotzingo y Cholula y Tepe[y]acac. Y ansí fue que ciertamente, como fidelísimos amigos, le ayudaron a ganar y a conquistar toda la máquina de este nuevo mundo con gran amor y voluntad; y, en todas las ocasiones que se le ofrecieron [a CORTÉS], siempre les halló muy prontos y a su lado, con determinación de seguirle hasta morir o vencer, contra sus propios naturales y patricios, amigos y confederados, aunándose con n[uest]ros españoles, gente extraña de su natural y nación, cuya causa se atribuye a ser más obra de Dios /201r/n[uest]ro señor que de hombre mortales, porque tenía guardada esta gente tan incógnita y apartada para ensalzamiento de su santa fe católica.

Acabada ésta plática, como referido tenemos, HER[NAN]DO CORTÉS, a la cual los cuatro $s$ [eñor]es de las cuatro cabeceras de Tlaxcala condescendieron en todo lo que les pidió, confirmando y ratificando su leal amistad, sin haber contrario otra cosa alguna, y dándole todo lo neces[ari]o, como les fue pedido, y saliendo número de gente para Cempuala, con capitanes prácticos y conocidos y experimentados en la guerra, para que con más recaudo se trujesen las cosas necesarias que les fuesen encargadas y entregadas con debido efecto, como se hizo, haciendo en éste uno de los más loables servicios que los tlaxcaltecas hicieron a CORTÉS y a la Corona Real de Castilla (267). 
El objetivo de esta escena es afianzar la directa participación en las acciones militares contra México-Tenochtitlan, incluyendo los términos de un "negocio" entre Cortés y los tlaxcaltecas junto con la promesa de un apoyo incondicional, "hasta morir o vencer". Destacamos, además, que la alianza no solo es terrenal sino también divina. Remarcamos también cómo en la escena se refiere a la participación de "capitanes prácticos y conocidos y experimentados en la guerra".

La escena prosigue declarando que la voluntad ulterior de Cortés: "era ir sobre México y asolarlo y destruirlo, y que, sin su parecer, no quería comenzar cosa alguna, porque, como a amigos verdaderos y leales, lo quería comunicar con ellos antes de principiar neg[ocio]o de tanta importancia" (Muñoz Camargo, Descripción 268). Frente a este negocio, indica Muñoz Camargo, "respondieron los cuatro s[eño]es de las cuatro cabeceras resolutam[ent]e que la guerra se comenzase como mejor le pareciese y ordenase, que ellos le seguirían e irían con él" (268).

Muñoz Camargo relata cómo los capitanes tlaxcaltecas proponen una estrategia focalizada en la conquista y el control de "la provincia de Tepe [y] ac y a todos sus alrededores y comarcas" a fin de "desmembrar y cortar las raíces del árbol, y que, quedando destroncado, que con más facilidad se derribaría" (268), es decir, impedir el apoyo militar y logístico desde de las "provincias sujetas a México" (268). En el cierre de la "plática y razonamiento", indica Muñoz Camargo en la Descripción de la ciudad y provincia de Tlaxcala:

Y, tomado México, todo lo demás se sujetaría con más facilidad, y que, no habiendo esto, tendría fuerzas para mandar sus gentes, y que habría gran riesgo y que no le faltarían fuerzas para resistirse grandes tiempos; $/ 211 \mathrm{v} /$ porque los suyos, de neces[ida]d, había de acudir a su señor, pues todas las provin[ci]as se gobernaban por $\mathrm{s}$ [eñor]es mexicanos.

Cuyo acuerdo y consejo quieren atribuir así, como referido tengo, los tlaxcaltecas; [pero] que fuese dado por ellos, o que fuese por los $\mathrm{n}$ [uest]ros, ellos fue de mucho ser y muy heróico consejo: por cuya orden y design[i]o se fue prosiguiendo la guerra, conquistándose y ganándose toda la redondez desde rei[n]o, especialm[ent]e los lugares más cercanos, de donde se presumía que podía venir socorro a México, hasta que, a honra y gloria de Dios n[uest]ro señor, se conquistó y pacificó toda la máquina desde nuevo mundo (268-269). 
El objetivo de la escena no es solamente retórico. La escena afirma el lugar de los tlaxcaltecas como indios conquistadores, como indios aliados y leales a la corona. Esto es evidente en el "acuerdo y consejo" que sigue la estrategia tlaxcalteca del "árbol destroncado" y que determina el cauce y el éxito de las acciones bélicas contra México-Tenochtitlan y sus aliados.

Asímismo, es plausible integrar un breve análisis sobre cinco imágenes relacionadas con las guerras y conquistas de españoles y tlaxcaltecas contra otros indios en diferentes latitudes mesoamericanas. Utilizaremos cinco imágenes que evocan la alianza político-militar tlaxcalteca e hispana (ver Anexos). La primera (Imagen 1) es el relato de la batalla de México-Tenochtitlan, donde la entrada de las tropas tlaxcaltecas por las calles y su enfrentamiento con los mexicas es evidente. Podemos ver también en la retaguardia a caballo un español apoyando el avance tlaxcalteca. La segunda (Imagen 2) responde a las guerras de conquista en Nueva Galicia. La tercera (Imagen 3) remite a la conquista de California. La cuarta (Imagen 4) a la conquista de Guatemala. Y la quinta (Imagen 5) a las guerras en la siempre conflictiva Oaxaca.

Es posible observar algunos patrones en estas imágenes. Distinguimos que en cada uno, españoles y tlaxcaltecas comparten el lado izquierdo de la escena. Decoradas con tocados y plumas, y claramente idenficables con sus estandartes, las tropas tlaxcaltecas acompañan a la caballería española, que reitera la iconografía de Santiago Mataindios (Matamoros) ${ }^{6}$. El lado derecho de la escena presenta a los otros indios, en clara actitud de resistencia armada. Asimismo, en el extremo superior derecho distinguimos los glifos nahuas que refieren al topónimo específico (Imágenes 2-5).

Como hemos señalado, buena parte de las imágenes de la Descripción corresponde a imágenes violentas relacionadas con las guerras de conquista en Mesoamérica. Empero, en nuestra selección de imágenes hay, por lo menos, dos dimensiones relacionadas. Por una parte, la participacion de los tlaxcaltecas en la conquista y colonización de diversas latitudes y, por otra, la validación de estas acciones frente al orden colonial. Es canónico que el objetivo de esta escenas es la aclaración y el posicionamiento de los tlaxcaltecas como colaboradores directos en las campañas de conquista.

\footnotetext{
Respecto a Santiago Mataindios relevamos la lectura de Javier Domínguez que analiza las continuidades iconográficas con el mundo medieval europeo, específicamente en la españolización de Jacobo con la figura de Santiago y luego su impacto en la conquista y colonización de Nueva España y el Perú.
} 
Pero también es sugerente pensar que las escenas de colaboración militar son parte de la reconstrucción de una historicidad que no olvida su lugar y que reconoce y afirma el impacto de sus acciones y auxilios, visualizándose como vencedores o bien como conquistadores (Añón 328-335, Martínez 37-70, Mignolo 451-484, Navarrete 288-310, Velasco 307-329).

En suma, consideramos que la noción de indios conquistadores no resulta indiferente al complejo proceso de negociaciones y compromisos llevados a cabo por tlaxcaltecas y españoles, en el horizonte de un objetivo políticomilitar común, una alianza, en la cual Tlaxcala tiene una posición activa y privilegiada. En la Descripición, entonces, hay evidencia de un discurso en movimiento que conduce a un giro en la lectura sobre la conquista y colonización de México y otras partes de Mesoamérica ${ }^{7}$. En este contexto, la Descripción nos invita a volver a pensar el lugar de los tlaxcaltecas como agentes activos, como indios conquistadores y civilizadores, en la reconstrucción del mundo cultural mesoamericano. Finalmente, la noción de indios conquistadores nos permite interpretar el relato de Muñoz Camargo como un relato que construye una posición de enunciación específica y constitutiva, podemos aventurar, de un proyecto civilizatorio indio, tlaxcalteca, en desarrollo dentro del orden colonial novohispano.

\section{CONSIDERACIONES FINALES}

Entonces, ¿por qué pensar al indio como conquistador?, ¿qué tipo de horizonte de pregunta se lleva a cabo con el posicionamiento del indio como vencedor $\mathrm{y}$, por cierto, cuál es su alcance en los procesos de creación e interacción cultural que le son concomitantes? En estas preguntas es posible reafirmar el valor teórico-metodológico de problematizar el lugar del indio en el Nuevo Mundo. Esto significa profundizar en cuestionamiento que involucra no solamente

7 Sobre este asunto destacamos el trabajo de José Rivera quien ha compilado y paleografeado documentos relacionados con el proyecto hispano de colonización del norte de Nueva España y, específicamente sobre la movilización de tlaxcaltecas en la diáspora de 1591. Detalles específicos sobre las condiciones para la colonización son bien expuestos por Rivera, a saber, los repartimientos de tierra, exenciones de servicios y licencias para montar a caballo, entre muchas otros. Rivera también destaca el contexto de la pacificación de la Gran Chichimeca y su efecto directo en la diseminación de la herencia cultural nahua transmitida por los colonizadores tlaxcaltecas a los pobladores fronterizos. 
el lugar del indio como colaborador, aliado o amigo, sino que por sobre todo lo ubica como pivote para problematizar aquello que hemos indicado como un proyecto civilizatorio indio, finalmente, un proyecto civilizatorio alternativo. Los alcances de esta propuesta civilizatoria demuestran que al posicionar al indio como conquistador es posible evidenciar un ejercicio de rearticulación de ciertos elementos determinantes en la construcción de su identidad cultural.

Por ello, pensar en el indio como conquistador es una invitación. Una invitación que nos ubica en un camino que aún no se ha completado. En este contexto, el relato de Diego Muñoz Camargo funciona para relevar, precisamente, cómo al realizar un análisis e interpretación de las crónicas mestizas es necesario también posicionar una perspectiva abierta a conceptualizaciones y perspectivas en las cuales sea posible reconocer nuevos contenidos. Entre ellos hemos propuesto la noción de indios conquistadores y sus corolarios de carácter civilizatorio. Hemos expuesto cómo en la Descripción se redireccionan no solo los acontecimientos de la conquista de México, sino también se rearticula la posición de enunciación de los propios tlaxcaltecas funcionalizando los hechos, aclarando éstos conforme a una narración en movimiento. En la noción de indios conquistadores se conjuga la crítica a la historia convencional de la conquista y colonización del Nuevo Mundo junto con la reinscripción de estos fenómenos en una historia alternativa donde los indios desempeñan un rol central. La perspectiva otorgada por la noción de indios conquistadores nos permite profundizar en el propósito de Muñoz Camargo al referir en su Descripción a la participación de tlaxcaltecas como conquistadores y aliados. Con ello, la lectura de los tlaxcaltecas como indios conquistadores conduce una reflexión sobre la elección civilizatoria que involucró sus propios intereses, motivaciones y objetivos político-militares.

Por lo tanto, es posible sostener que en la Descripción se desarrolla la reinscripción de una subjetividad alternativa. Esta subjetividad alternativa se muestra en el relato escritural y pictográfico sobre los conquistadores tlaxcaltecas, desde la positividad discursiva de los elementos históricoculturales sobrevivientes y resemantizados en el encuentro-choque con el proyecto civilizatorio moderno-occidental. A través del relato de la Descripción es posible comprender la operatividad del encuentro-choque y evidenciar también la bifurcación de un proyecto civilizatorio que, en este caso, se genera en Tlaxcala. Ejemplos tales como la Descripción nos permiten comprender el ejercicio de reinscripción que pone en juego los modos de apropiación y adaptación de prácticas y discursos, negociaciones y acuerdos, desde los 
cuales articuló una alianza político-militar con el orden colonial. Más allá del colaboracionismo tlaxcalteca, que olvida la condición humana de la violencia y el conflicto, idealizando (y esencializando) al indio, en la Descripción resuena el eco de los indios como agentes directos de la reconstrucción del mundo cultural novohispano.

Finalmente, la obra de Muñoz Camargo nos muestra la continuidad escritural y pictográfica de la experiencia histórica de un grupo de indios, los tlaxcaltecas, como conquistadores y, ciertamente, como civilizadores, es decir, como agentes del cambio cultural que determinó el destino de todo un mundo nuevo. Por lo tanto, la Descripción es también una obra estratégica, ofensiva, funcional y operacional, donde todavía hay lugar para volver a preguntar por un modo alternativo, un modo indiano, en el desarrollo de la conquista y colonización americanas.

\section{BIBLIOGRAFÍA}

Acuña, René. Descripción de la ciudad y provincia de Tlaxcala. Una respuesta a Hanns. Prem. México: Universidad Nacional Autónoma de México, 1986.

"Estudio preliminar". Descripción de la ciudad y provincia de Tlaxcala de las Indias y del mar océano para el buen gobierno y ennblecimiento dellas. México: Universidad Nacional Autónoma de México, 1981. 8-49.

Añón, Valeria. La palabra despierta. Tramas de la identidad y usos del pasado en crónicas de la conquista de México. Buenos Aires: Corregidor, 2012.

Chavero, Alfredo. El Lienzo de Tlaxcala. México: Universidad Nacional Autónoma de México, 1979.

Chuchiak, John. "Forgotten Allies. The Origins and Roles of Native Mesoamerican Auxiliaries and Indios Conquistadores in the Conquest of Yucatan, 1526-1550". Indian Conquistadors. Indigenous Allies in the Conquest of Mesoamerica. Ed. Laura Matthew y Michel Oudijk. Oklahoma: Norma - University of Oklahoma Press, 2007. 175-226.

Cortés, Hernán. Cartas de Relación. Madrid: Dastin, 2003.

Díaz del Castillo, Bernal. Historia verdadera de la conquista de la Nueva España. México: Alianza, 1991.

Domínguez, Javier. De apóstol matamoros a yllapa mataindios: dogmas e ideologías medievales en el (des)cubrimiento de América. Salamanca: Universidad de Salamanca, 2008.

Domínguez, Mónica. Military Ethos and Visual Culture in Post-Conquest Mexico. Dorchester: Dorset Press, 2013.

Escalante, Pablo. Los códices mesoamericanos antes y después de la conquista española. México: Fondo de Cultura Económica, 2010. 
Farriss, Nancy. "Recordando el futuro, anticipando el pasado. Tiempo histórico y tiempo cósmico entre los mayas de Yucatán". La memoria y el olvido. Segundo simposio de historia de las mentalidades. México: Instituto Nacional de Antropología e Historia, 1985. 47-60.

Gibson, Charles. "The identity of Diego Muñoz Camargo". The Hispanic American Historical Review 30 (1950): 195-208.

Gruzinski, Serge. La guerra de las imágenes. De Cristóbal Colón a "Blade Runner" (14922019). México: Fondo de Cultura Económica, 2006.

La colonización de lo imaginario. Sociedades indígenas y occidentalización en el México español. Siglos XVI-XVIII. México: Fondo de Cultura Económica, 2004.

Güereca, Raquel. Milicias indigenas en la Nueva España. Reflexiones desde el derecho indiano sobre los derechos de guerra. México: Universidad Nacional Autónoma de México, 2016.

Holder, Paul. Studies in the Auxilia of the Roman Army from Augustus to Trajan. Oxford: British Archaeological Reports, 1980.

Lienhard, Martin. "La crónica mestiza en México y el Perú hasta 1620: Apuntes para su estudio histórico-literario". Revista de Crítica Literaria Latinoamericana 17 (1983): 105-115.

Lockhart, James. "Introduction: Background and Course of the New Philology". The Wired Humanities Project: University of Oregon. Enero 2007. http://whp.uoregon.edu/Lockhart/ Intro.pdf

The Nahuas After the Conquest. A Social and Cultural History of the Indians of Central Mexico, Sixteenth Through Eighteenth Centuries. Stanford: Stanford University Press, 1992.

López Austin, Alfredo. Hombre-Dios. México: Universidad Nacional Autónoma de México, 2013.

Matthew, Laura y Michel Oudijk, ed. Indian Conquistadors. Indigenous Allies in the Conquest of Mesoamerica. Oklahoma: Norma - University of Oklahoma Press, 2007.

Martínez, Andrea. Un gobierno de indios: Tlaxcala 1519-1750. México: Fondo de Cultura Económica, 2008.

"Las pinturas del Manuscrito de Glasgow y el Lienzo de Tlaxcala". Revista de Cultura Náhualt 20 (1990): 141-162.

Mignolo, Walter. "El mandato y la ofrenda: La Descripción de la Ciudad y Provincia de Tlaxcala, de Diego Muñoz Camargo, y las Relaciones de Indias". Nueva Revista de Filología Hispánica 35/2 (1987): 451-484.

Muñoz Camargo, Diego. Descripción de la ciudad y provincia de Tlaxcala de las Indias y del mar océano para el buen gobierno y ennblecimiento dellas. [1584]. México: Universidad Nacional Autónoma de México, 1981.

Descripción de la ciudad y provincia de Tlaxcala de las Indias y del mar océano para el buen gobierno y ennblecimiento dellas. [1584]. San Luis Potosí: El Colegio de San Luis - Gobierno del Estado de Tlaxcala, 2000.

Historia de Tlaxcala [1590]. México: Universidad Autónoma de Tlaxcala, 2013.

Navarrete, Federico. "La Malinche, la Virgen y la montaña: el juego de la identidad en los códices tlaxcaltecas". Historia 26/2 (2007): 288-310.

Nietzsche, Friedrich. Asi habló Zaratustra. Madrid: Alianza, 1998. 
Nuñez Rodríguez, Manuel. "El Lienzo de Tlaxcala. ¿Otra forma de escribir la historia?”. Semata, Ciencias Sociales y Humanidades 24 (2012): 55-72.

O`Gorman, Edmundo. La invención de América. México: Fondo de Cultura Económica, 2001. Powell, Philip. La Guerra Chichimeca (1550-1600). México: Fondo de Cultura Económica, 1975.

Prem, Hanns. "Descripción de la ciudad y provincia de Tlaxcala de las Indias del Mar Océano para el buen gobierno y ennoblecimiento dellas by Diego Muñoz Camargo, René Acuña". Zeitschrift für Ethnologie 110/2 (1985): 315-316.

Restall, Matthew. Seven Myths of the Spanish Conquest. New York: Oxford University Press, 2003.

Restall, Matthew y Michel Oudijk. "Mesoamerican Conquistadors in the Sixteenth Century". Indian Conquistadors. Indigenous Allies in the Conquest of Mesoamerica. Ed. Laura Matthew y Michel Oudijk. Oklahoma: Norma - University of Oklahoma Press, 2007. 28-64.

Rivera, José. Documentos inéditos para el estudio de los tlaxcaltecas en San Luis Potosí, siglos XVI-XVIII. Vol. III. Tlaxcala: Gobierno del Estado de Tlaxcala, 2010.

Los tlaxcaltecas: pobladores de San Luis Potosí. San Luis Potosí: Colegio de San Luis, 1999.

Ruiz Esquide, Andrea. Los indios amigos en la frontera araucana. Santiago: Dirección de Archivos y Bibliotecas y Museos, 1993.

Schroeder, Susan, ed. The Conquest All Over Again: Nahuas and Zapotees Thinking, Writing, and Painting Spanish Colonialism. Brighton: Sussex Academic Press, 2010.

Velasco, Salvador. "El 'coloquio de Tlaxcala' de Diego Muñoz Camargo". Estudios de Cultura Náhuatl 34 (2003): 307-329.

Vinson, Ben y Matthew Restall. "Black Soldiers, Native Soldiers. Meanings of Military Service in the Spanish American Colonies". Beyond Black and Red: African-native Relations in Colonial Latin America. Ed. Matthew Restall. Albuquerque: University of New Mexico Press, 2005. 15-52. 


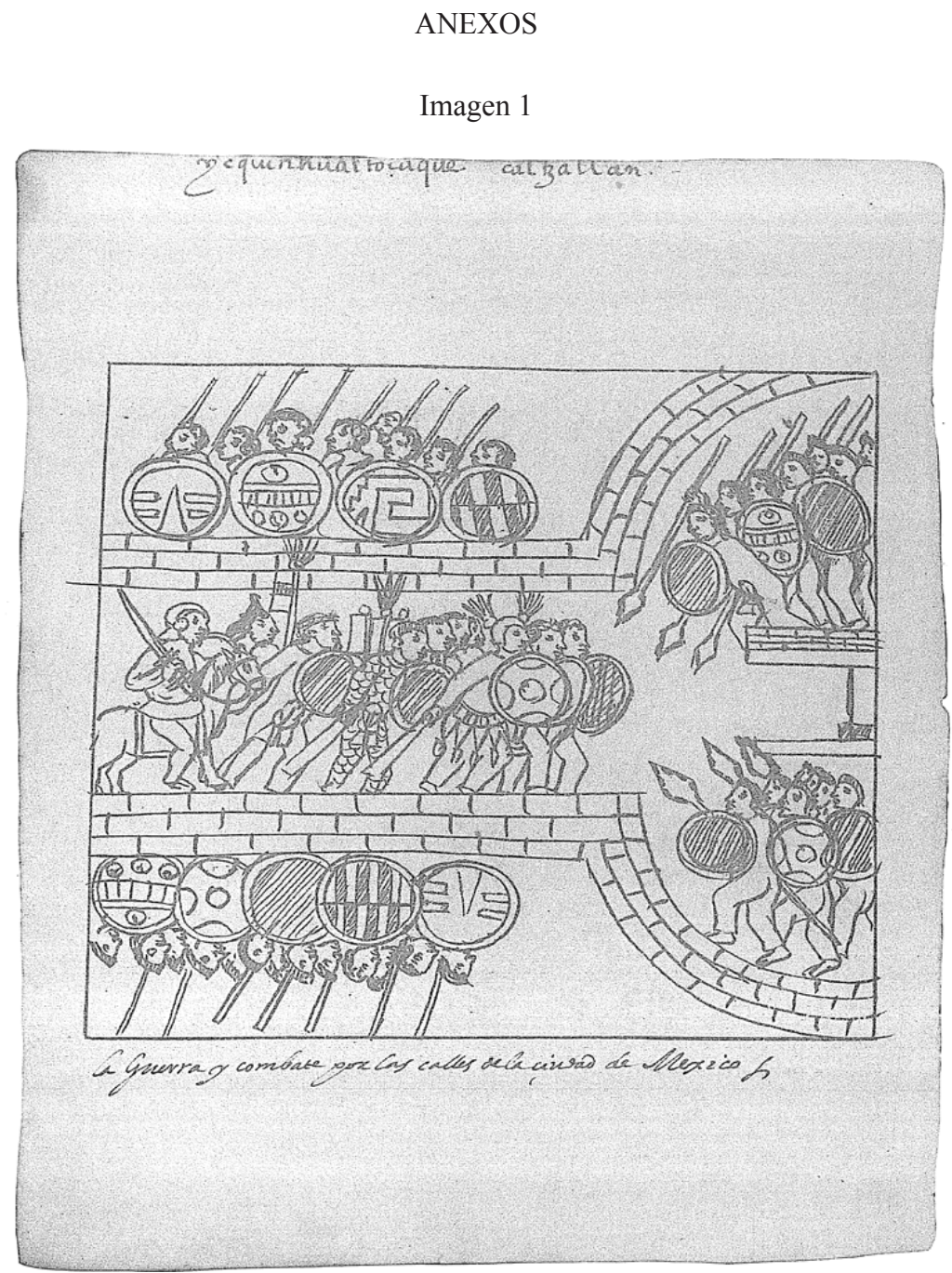

Yc quinhualtocaque caltzallan [así los siguieron entre las casas]

La guerra y combate por las calles de la ciudad de México

Muñoz Camargo, Diego. Descripción de la ciudad y provincia de Tlaxcala de las Indias y del mar océano para el buen gobierno y ennblecimiento dellas. [1584]. México: Universidad Nacional Autónoma de México, 1981. 
Imagen 2

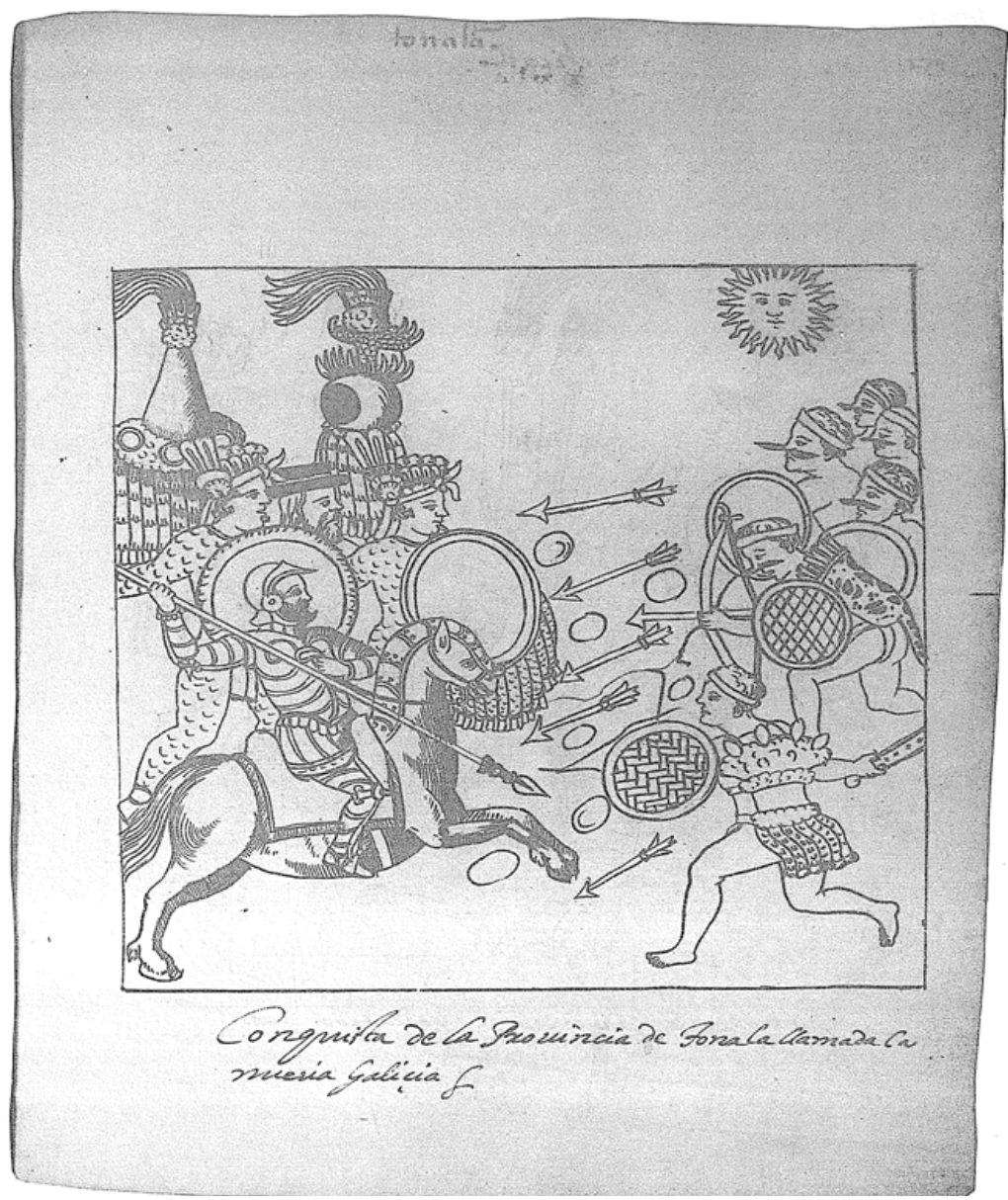

Tonalan

Conquista de la provincia de Tonala, llamada la Nueva Galicia

Muñoz Camargo, Diego. Descripción de la ciudad y provincia de Tlaxcala de las Indias y del mar océano para el buen gobierno y ennblecimiento dellas. [1584]. México: Universidad Nacional Autónoma de México, 1981. 


\section{Imagen 3}

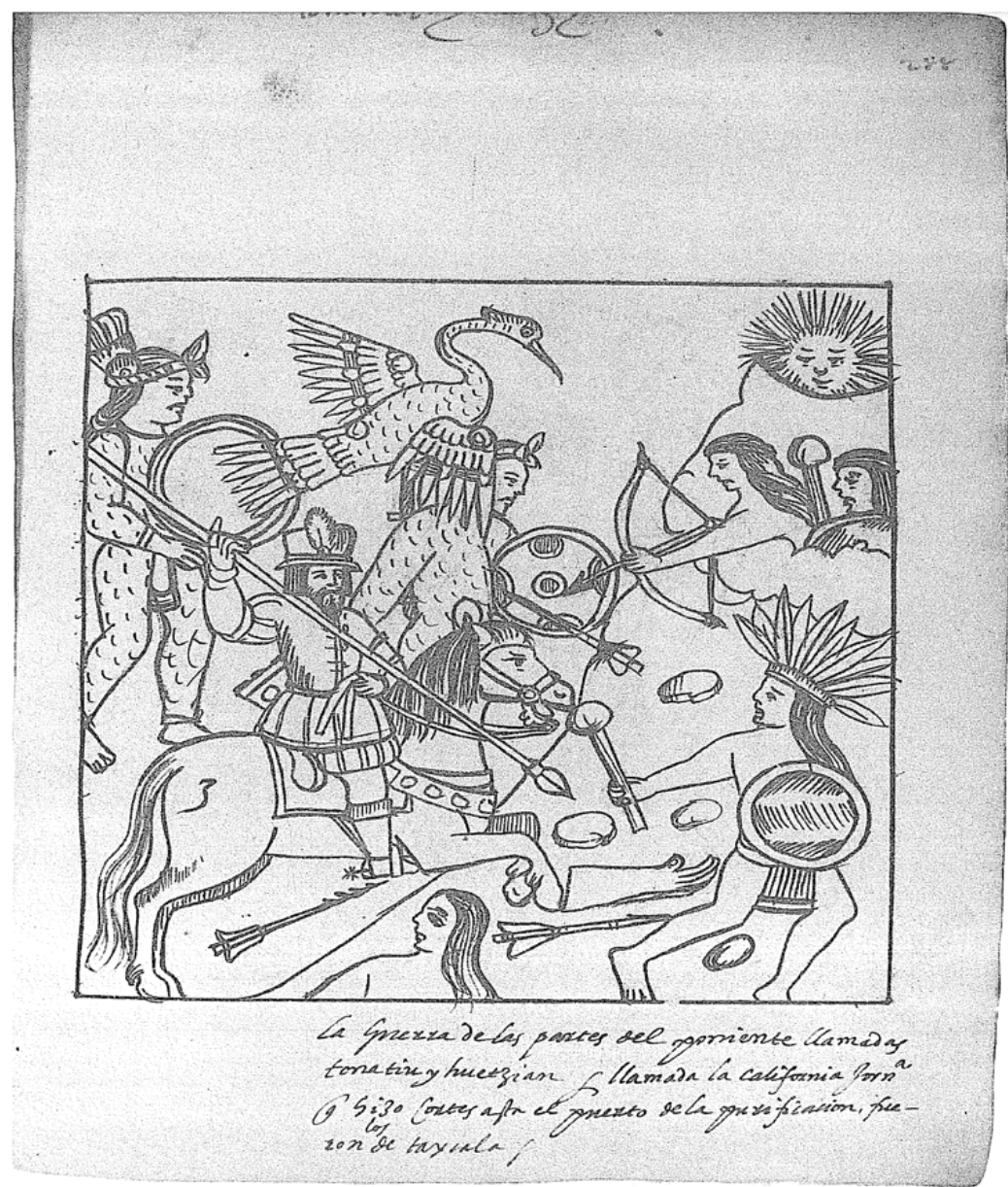

La guerra de las partes del poniente llamadas Tonatin y Huetzian y llamada la California forma que hizo Cortés [h]asta el puesto de la pacificación, fueron los de T[1]axcala

Muñoz Camargo, Diego. Descripción de la ciudad y provincia de Tlaxcala de las Indias y del mar océano para el buen gobierno y ennblecimiento dellas. [1584]. México: Universidad Nacional Autónoma de México, 1981. 


\section{Imagen 4}

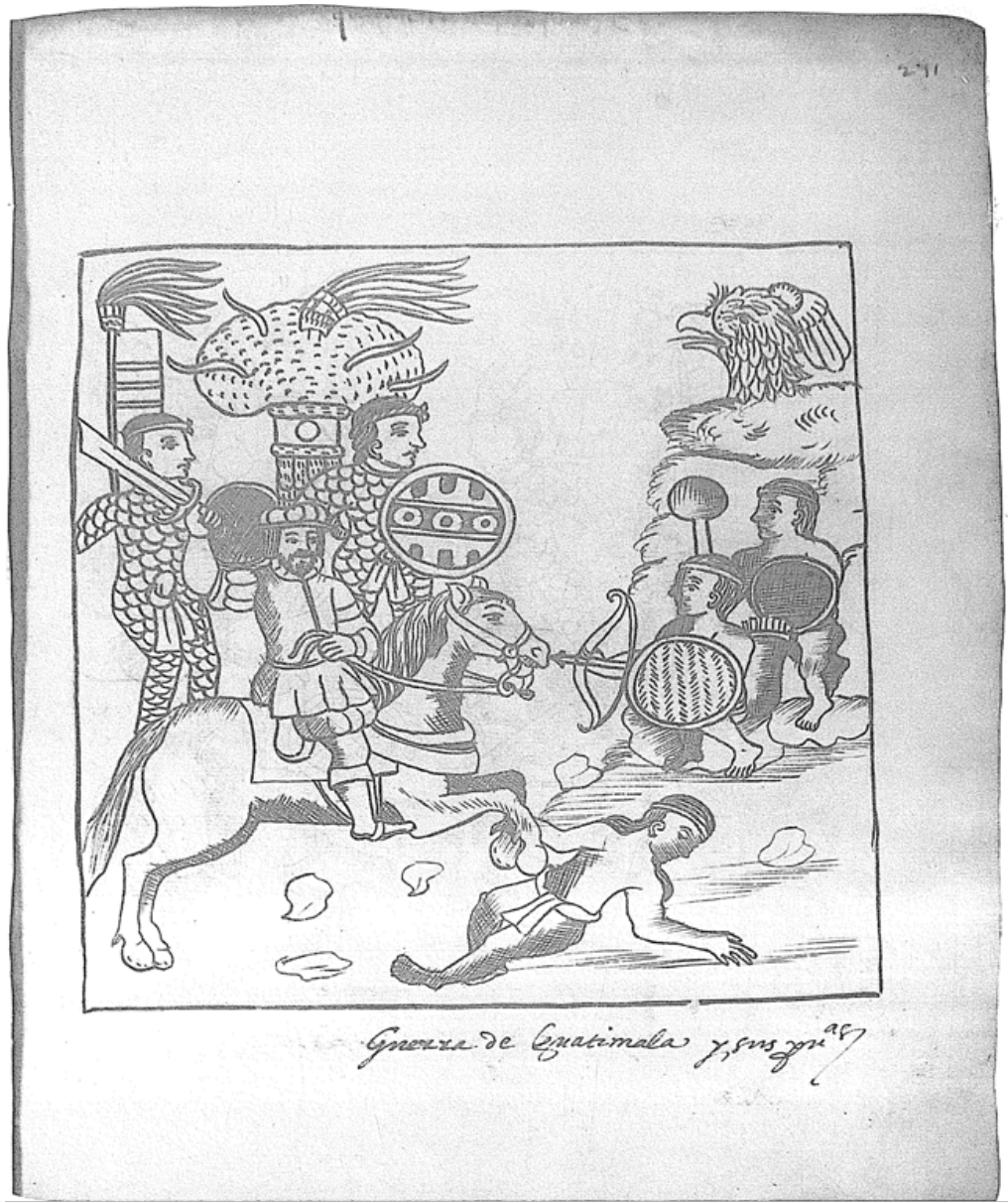

Guerra de Guatemala y sus provincias

Muñoz Camargo, Diego. Descripción de la ciudad y provincia de Tlaxcala de las Indias y del mar océano para el buen gobierno y ennblecimiento dellas. [1584]. México: Universidad Nacional Autónoma de México, 1981. 


\section{Imagen 5}

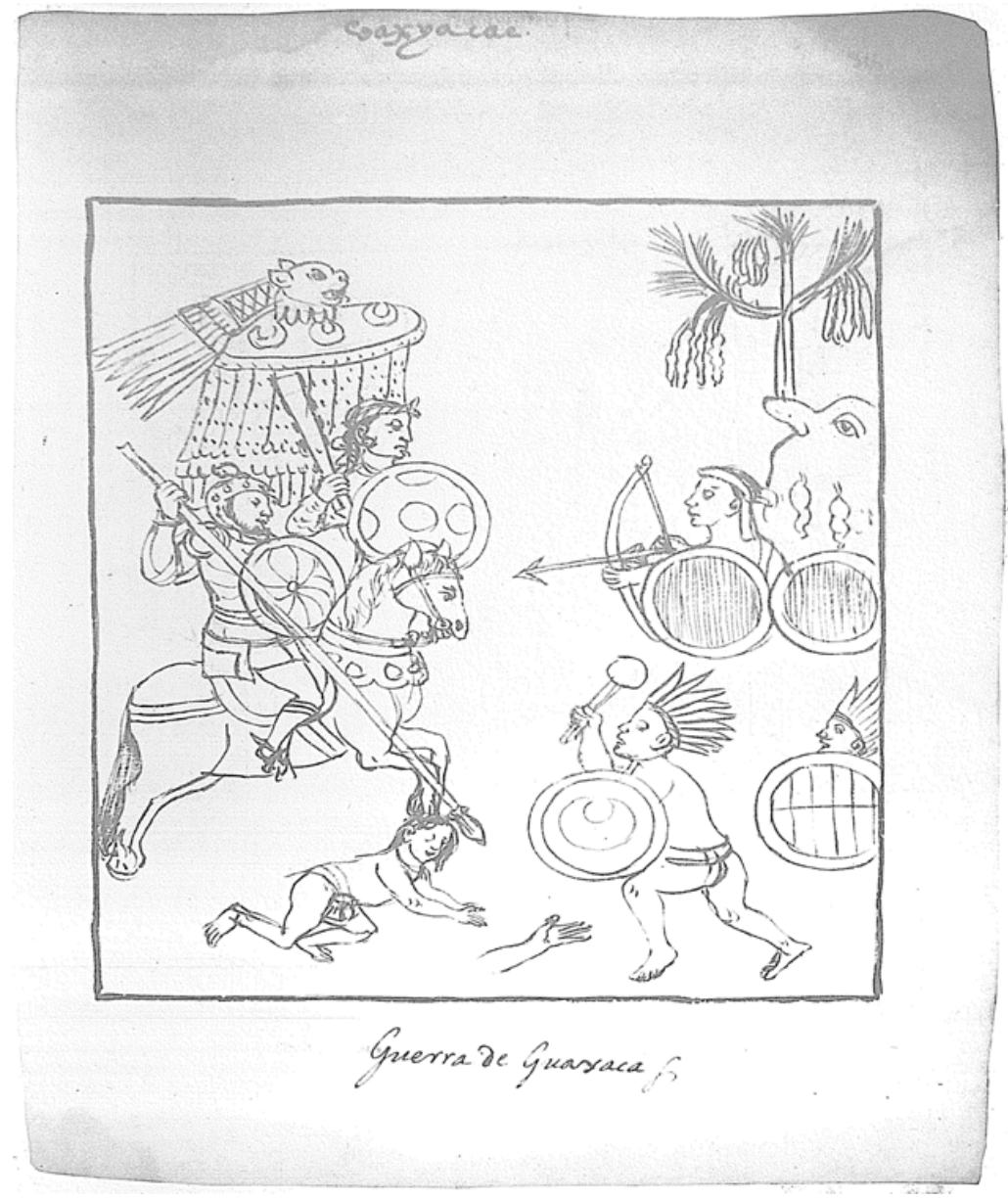

Guerra de Guaxaca

Muñoz Camargo, Diego. Descripción de la ciudad y provincia de Tlaxcala de las Indias y del mar océano para el buen gobierno y ennblecimiento dellas. [1584]. México: Universidad Nacional Autónoma de México, 1981. 